\title{
Tacrolimus versus Cyclosporine- Comparative Evaluation as First line drug in Vernal keratoconjuctivitis
}

\author{
Rashmi Kumari ${ }^{1}$, Bhawesh Chandra Saha ${ }^{2}$, Bibhuti Prasanna Sinha ${ }^{3}$, Nilesh Mohan ${ }^{4}$ \\ ${ }^{1}$ Senior resident, RIO, IGIMS Patna \\ ${ }^{2}$ Senior resident AIIMS Patna \\ ${ }^{3}$ Additional Professor, HOD, RIO, IGIMS ,Patna \\ ${ }^{4}$ Associate Professor, RIO, IGIMS, Patna
}

\begin{abstract}
Introduction: The aim of the study was to evaluate and compare the efficacy, side effects and recurrence rate of vernal kerato conjunctivitis (VKC) with $0.03 \%$ tacrolimus and $0.05 \%$ cyclosporin. Material and method: A prospective randomised double blinded comparative study was conducted at a tertiary eye center. 46 Patients of VKC between March 2015- August 2015 were randomly divided into two groups and treated for 6 weeks with either Tacrolimus $(0.03 \%)$ eye ointment BD or Cyclosporine $(0.05 \%)$ eyedrops QID.The main outcome measures were scoring and comparison of Total subjective symptom scores (TSSS) and Total objective ocular sign scores (TOSS) within and between the Groups at each follow up. Thirty two patients, sixteen from each group, with comparable baseline characters were analysed. Results: With treatment both TSSS and TOSS decreased consistently in both groups without any adverse effects but an increase in scores was noticed within two weeks after drug withdrawal. Conclusion: Both drugs are equally effective and safe in VKC but with short lasting effect.
\end{abstract}

Key words: VKC,TOSS, TSSS

\section{Introduction}

Vernal keratoconjunctivitis (VKC) is a chronic inflammatory ocular condition of children and adolescents. Besides being an annoying allergic eye disease, sometimes it can be sight threatning. It usually occurs before 10 years of age with a male-female ratio about 2:1(Collum MT,1999). Although the disease generally follows a self limiting course, generally lasting 2-10 years and ordinarily resolves by puberty, proper management of its active phase is warranted to prevent any dreaded complication.

Received: 25/12/16

Corresponding author

Accepted: 16/06/17

Dr Rashmi kumari,

Senior resident,

Indira Gandhi Institute of medical sciences,(IGIMS,Patna)

E mail; dr.rchandras08@gmail.com
$\mathrm{VKC}$ is quite prevalent in countries surrounding the Mediterranean, in West and central African nations, in the Middle-East and in Japan owing to their warm climate all around (Collum MT,1999).

A typical set of signs and symptoms exists for this pathology with acute onset which can easily be identified especially from the months of April to August, although some patients might have a perennial form of the disease with some typical signs in their eyes. Depending upon the predominant area of ocular surface affected, three forms of the disease have been observed, i.e. limbal, tarsal and mixed VKC, Neumann et al,1959). The classical symptoms 
of VKC include intense itching, tearing, mucous secretions and severe photophobia (Bielory et al,2000). Typical conjunctival signs comprise hyperemia, papillary hypertrophy, giant papillae, discharge, and Horner-Trantas dots (accumulation of gelatinous inflammatory infiltrates around the limbus) (Leonardi et al 2002).

A significant association with atopy has been established in majority of VKC patients and a positive family history can be elicited in about two-third of the patients.

Although the precise immunopathogenic mechanism is still not clear but definitely it is more complex than a simple type 1 hypersensitivity reaction challenging the established facts. Some recent research further emphsizes the fact of complex underlying pathophysiology since negative skin test is quite frequently observed among these cases (Staphl et al,2004). These assumptions are further strengthened by the histopathological examination of conjunctiva demonostrating chronic inlammatory cells like lymphocytes and macrophages as a part of infiltration along with acute inflammatory cells like eosinophils, degranulated mast cells, basophils, plasma cells signifying the involvement of Type IV hypersensitivity reaction as well. Moreover, cell culture from conjunctival scraping of VKC patients elicited mainly Type 2 Helper $T$ cells clones (Bonini et al,2004). Conjunctiva of these patients shows increased presence of cytokines like IL-4, IL-5, IL-13, growth factors and enzymes which are basically derivative of Type 2 Helper $\mathrm{T}$ cells. Their increased production in VKC may, in part, be responsible for tissue remodelling and papillae formation on tarsal conjunctiva. This insight of the pathophysiology has paved the use of certain recent drugs (immunomodulators) like cyclosporine and tacrolimus while the conventional therapy includes topical steroids, NSAIDS, vasoconstrictors, antihistamines, mast cell stabilizers. They act by dual mechanism, that is inhibiting activation of $\mathrm{T}$ cells, and also inhibiting IgE-dependent histamine release from mast cells and basophils (Cook EB et $\mathrm{al}, 2004)$. Both drugs act on their target cells via cyclophyllin receptors. Tacrolimus (FK506) is a macrolide antibiotic that has potent immunomodulatory properties. It acts primarily on T-lymphocytes by inhibiting production of cytokines, particularly IL-2, IL-3, IL-5, TNF- $\alpha$ and IFN- $\gamma$ (Schreiber SL et al,1992)

The most effective treatment for VKC have been topical corticosteroids, but it carries considerable risk of complications like cataract, glaucoma and secondary infections which may even lead to permanent visual impairment (Tabbara KF,1999). Thus there is need for an alternative, effective, safe drug that can decrease the morbidity from this potentially blinding disease.

Both cyclosporine A and tacrolimus have achieved breakthrough results in the treatment of severe allergic eye diseases, and are considered to be well tolerated with negligible side-effects according to many recent studies (Pucci et al,2002 and Vichyanond P et al,2004).. Cyclosporine eye drops were found to be effective in treating severe VKC. However, burning with $2 \%$ cyclosporine was unacceptable to several patients and led to low compliance (Gupta et al,2001 and De Smedt S et al 2012).

Tacrolimus ointment has shown satisfactory results in treatment of recalcitrant VKC.. Adverse effect from $0.1 \%$ tacrolimus ointment in some study report only transient stinging effect. Systemic absorption of FK-506 from conjunctival surface was found to be minimal.

So the aim of our study was to evaluate the efficacy and safety of these two immunomodulators as first line drug in VKC and also to compare their relative effectiveness at lowest available concentration. 


\section{Material and methods}

A prospective randomised double blinded comparative clinical study was designed. Ethical clearance was taken from the hospital ethics committee of Indira Gandhi Institute of Medical sciences,Patna. Diagnosis of VKC was made clinically according to the presence of classical signs and symptoms. Clinical Scoring System of Bleik et al,1991, (table1) was used to grade the signs and symptoms. The guardians of verbal children or adolescent with active disease that is total subjective symptom score,TSSS $>6$ \& total objective sign score, TOSS $>4$ presenting in the out patients department(OOD) between march 2015-august 2015 were explained about the study. Those who agreed for the regular follow ups were included after taking proper written informed consent.
Presence of co-existing ocular diseases such as glaucoma, uveitis, corneal disease, ocular infection, systemic illness like hepatic or renal dysfunction and any reported hypersensitivity to FK-506 or cyclosporine formed the basis for exclusion from the trial.

Complete general, physical and ophthalmologic examinations were done. Patients were advised to discontinue all topical and oral allergic drugs, if any, for 2-weeks after which they were examined and their baseline symptoms (TSSS) as well as signs(TOSS) were recorded on the basis of table1 and then were randomly assigned to one of the two study groups by a computer generated system.

\begin{tabular}{|l|l|}
\hline $\begin{array}{l}\text { Grading of Symptoms(Bleik et al) } \\
\text { Itching, tearing, photophobia, discharge and foreign body sensation }\end{array}$ \\
\hline 0 & indicating no symptoms \\
\hline $1+$ & mild symptoms of discomfort which were just noticeable \\
\hline $2+$ & $\begin{array}{l}\text { moderate discomfort noticed most of the day but did not interfere with daily } \\
\text { routine activities }\end{array}$ \\
\hline $3+$ & severe symptoms interfering with daily routine activities \\
\hline $\begin{array}{l}\text { Grading of Signs } \\
\text { Conjunctival hyperemia }\end{array}$ \\
\hline 0 & no evidence of bulbar hyperaemia \\
\hline $1+$ & mild bulbar hyperaemia \\
\hline $2+$ & moderate bulbar hyperemia. \\
\hline $3+$ & severe bulbar hyperaemia \\
\hline Palpebral conjunctival papillae \\
\hline 0 & no papillary hypertrophy of the palpebral conjunctiva \\
\hline $1+$ & mild papillary hypertrophy \\
\hline $2+$ & moderate papillary hypertrophy (hazy view of the deep tarsal vessels). \\
\hline $3+$ & $\begin{array}{l}\text { severe papillary hypertrophy (deep tarsal vessels not visible in more than } 50 \% \text { of } \\
\text { the surface). }\end{array}$ \\
\hline Punctate keratitis \\
\hline 0 & no evidence of punctate keratitis \\
\hline $1+$ & one quadrant of punctate keratitis \\
\hline $2+$ & two quadrants of punctate keratitis \\
\hline
\end{tabular}




\begin{tabular}{|l|l|}
\hline $3+$ & three or more quadrants of punctate keratitis \\
\hline \multicolumn{2}{|l|}{ Trantas'dots } \\
\hline 0 & no evidence of dots.. \\
\hline $1+$ & 1 to 2 dots \\
\hline $2+$ & 3 to 4 dots \\
\hline $3+$ & more than 4 dots \\
\hline Limbal infiltration \\
\hline 0 & no evidence of limbal infiltrates \\
\hline $1+$ & less than 900 of limbal infiltrates \\
\hline $2+$ & less than 1800 of limbal infiltrate but more than 900. \\
\hline $3+$ & more than 1800 of limbal infiltrate. \\
\hline
\end{tabular}

\section{Table 1- clinical scoring system (Bleik et al,1991)}

Group A received Tacrolimus ointment $(0.03 \%) \mathrm{BD}$, a placebo eye drop (normal saline) QID and Group B recieved Cyclosporine e/d $(0.05 \%)$ QID along with placebo eye ointment (soft white paraffin) BD along with cold compression for 6 weeks.Follow up was done fort nightly for 8 weeks ( 6 weeks with treatment and 2 weeks after completion of treatment).

The main outcome was measured in terms of Total subjective symptom scores (TSSS) and total objective ocular sign score (TOSS) before and after treatment at each visit. Secondary outcomes included scoring of transient side effects of medications and recurrence of symptoms and signs 2 weeks after treatment completion.

Transient ocular discomfort from drugs such as burning, blurring, stinging, ocular pain, periorbital edema, periorbital rash and headache were evaluated within 30 minutes after administration of the medications and were graded from 0-3 depending upon increasing severity.

All data were analysed with the statistical package for social sciences (SPSS). Continuous variables are presented as mean \pm standard deviations (SD's) and the categorical variables as percentages. Student's t-tests were used to determine the significance of the differences between means in the variables that were normally distributed. The Wilcoxon signed-rank tests were used for paired samples when the data were not normally distributed. Comparison of TSSS, TOSS and side effect scores between and within group at different time points (at entry, weeks 2, 4, 6and 8) was performed by ANOVA with repeated measure analysis and with Bonferroni corrections. The p-value $<0.05$ were considered to be statistically significant.

\section{Results}

A total of 46 patients were enrolled into this study, 35 (19 from group A and 16 from group B) completed the follow up. Demographic history revealed that most of the patients lost to follow up were from remote area of Bihar and majority of them attended 1 or two follow ups randomly and hence were excluded while evaluating the results. Only 2 out of 46 patients never turned back. Hence 32 patients, 16 from each group, with complete follow up were analysed. Out of the 32 patients, 28 were male with a mean age of $8.06( \pm 1.94)$ years in Group A and $7.12( \pm 1.66)$ years in Group B, the difference between the two being statistically insignificant $(\mathrm{p}=0.33)$ (Table 2$)$. Median duration of disease was 13 months and tarsal VKC was the most common form of presentation $(n=24)$ followed by mixed type $\operatorname{VKC}(\mathrm{n}=5)$ and limbal variant $(\mathrm{n}=3)$ (Table 2$)$ in both groups. 
Twenty eight patients were on some form of treatment for VKC before enrollment (topical steroid and olopatadine - 20 patients, ketorolac and olopatadine - 8 patients). Four patients were newly diagnosed case of VKC that had not been treated previously with any drug at presentation.

The five major complaints recorded by patients were itching (32 patients, 100\%), discharge (28 patients, $87 \%$ ), tearing (30 patients,
93.75\%), photophobia ( 9 patients, $28.12 \%$ ) and foreign body sensation 11 patients, $34.37 \%$ ). Associated allergic diseases noted were allergic rhinitis (31\%), asthma (6\%) and atopic dermatitis (3\%). Base line Total subjective symptom score (TSSS) in the Group A was $7.06( \pm 2.59)$ and in Group B was $7.75( \pm 2.90)$ the difference being clinically insignificant, $\mathrm{p}=$ 0.6. Baseline Total ocular sign score (TOSS) in both the groups were $4.88( \pm 1.5)$ and $4.5( \pm 1.15)$ respectively, $p=0.8$, (Table 2$)$.

\begin{tabular}{|c|c|c|c|c|}
\hline & $\begin{array}{l}\text { Tacrolimus } \\
\text { group }(n=16)\end{array}$ & $\begin{array}{l}\text { Cyclosporine } \\
\text { group }(n=16)\end{array}$ & $p$ value & $\begin{array}{l}\text { Total } \\
(n=32)\end{array}$ \\
\hline Male & 15 & 13 & & 28 \\
\hline Female & 1 & 3 & & 4 \\
\hline $\begin{array}{l}\text { Mean Age ( } \pm \text { SD) } \\
\text { Range(years) }\end{array}$ & $\begin{array}{l}8.06( \pm 1.94) \\
5-12\end{array}$ & $\begin{array}{l}7.12( \pm 1.66) \\
5-11\end{array}$ & $P=0.30$ & $\begin{array}{l}7.62( \pm 1.82) \\
5-12\end{array}$ \\
\hline $\begin{array}{l}\text { Median duration of } \\
\text { disease(months). } \\
\text { Range }\end{array}$ & $\begin{array}{l}14 \\
1-36\end{array}$ & $\begin{array}{l}12 \\
24 \\
24\end{array}$ & & 13 \\
\hline $\begin{array}{l}\text { Associated atopic conditions } \\
\text {-Allergic rhinitis } \\
\text {-Asthma } \\
\text {-Atopic } \\
\text { dermatitis }\end{array}$ & $\begin{array}{l}6 \\
2 \\
0\end{array}$ & $\begin{array}{l}4 \\
0 \\
1\end{array}$ & & $\begin{array}{l}10(31.25 \%) \\
2(6.25 \%) \\
1(3.125 \%)\end{array}$ \\
\hline $\begin{array}{l}\text { Type of VKC } \\
\text { Tarsal } \\
\text { Limbal } \\
\text { Mixed }\end{array}$ & $\begin{array}{l}11 \\
3 \\
2\end{array}$ & $\begin{array}{l}13 \\
0 \\
3\end{array}$ & & $\begin{array}{l}24(75 \%) \\
3(9.37 \%) \\
5(15.62 \%)\end{array}$ \\
\hline $\begin{array}{l}\text { Total subjective symptom score } \\
\text { (TSSS) }\end{array}$ & $7.06( \pm 2.59)$ & $7.75( \pm 2.90)$ & $p=0.6$ & \\
\hline Total ocular sign score(TOSS) & $4.88( \pm 1.5)$ & $4.5( \pm 1.15)$ & $p=0.8$ & \\
\hline
\end{tabular}

Table 2. Demographic characteristics and disease severity

There was reduction in TSSS in both the groups from 2 weeks onwards which was statistically significant at 4weeks $(\mathrm{p}<0.05)$ when compared to baseline values and was maintained till the completion of the course (6weeks). But the difference between the two groups $(p=0.54)$ was not significant (Table 3,Figure1).

\begin{tabular}{|c|c|c|c|}
\hline VARIABLE & $\begin{array}{l}\text { TACROLIMUS } \\
\text { GROUP }(\mathrm{n}=16)\end{array}$ & $\begin{array}{l}\text { CYCLOSPORINE } \\
\text { GROUP }(n=16)\end{array}$ & p value ${ }^{*}$ \\
\hline & MEAN ( $95 \%$ C I**) & MEAN ( $95 \%$ C I**) & \\
\hline BASELINE & $7.06(5.68-8.44)$ & $7.75(6.19-9.36)$ & $p=0.48$ \\
\hline $2^{\mathrm{ND}}$ WEEKS & $4.68(3.78-5.59)$ & $3.875(3.29-4.45)$ & $p=0.1181$ \\
\hline $4^{\mathrm{TH}}$ WEEKS & $\begin{array}{l}2.75(2.38-3.11) \\
p=0.004\end{array}$ & $\begin{array}{l}2.56(2.01-3.11) \\
p=0.004\end{array}$ & $p=0.548$ \\
\hline $6^{\text {TH }}$ WEEKS & $\begin{array}{l}1.31(0.99-1.63) \\
p=0.001\end{array}$ & $\begin{array}{l}1.18(0.83-1.53) \\
p=0.001\end{array}$ & $p=0.578$ \\
\hline $8^{\text {TH }}$ WEEKS & $\begin{array}{l}3.87(3.33-4.42) \\
p=0.03\end{array}$ & $\begin{array}{l}3.75(2.98-4.51) \\
p=0.03\end{array}$ & $p=0.779$ \\
\hline
\end{tabular}

Table3 ;Total subjective symptom scores at different visits(TSSS)

* t test for dfference of mean, ** confidence interval 


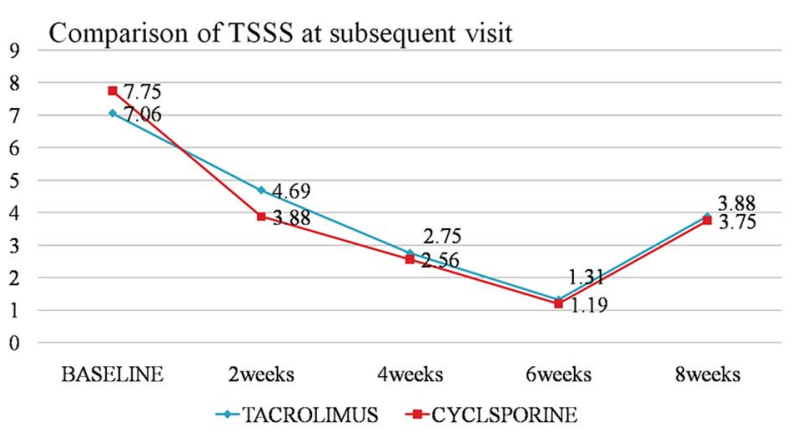

Fig 1. Graphical plot of total subjective symptom score at different folow up The total objective sign score, TOSS showed consistent decrease in subsequent visit in both the Groups and it was statistically significant, when compared to baseline, at week 6th week in both the groups $(\mathrm{p}<0.01)$ (Table 4,figure 2$)$. No difference in TOSS between the two treatment groups was observed at any time points.

\begin{tabular}{|c|c|c|c|}
\hline VARIABLE & $\begin{array}{l}\text { TACROLIMUS } \\
\text { GROUP }(\mathrm{n}=16)\end{array}$ & $\begin{array}{l}\text { CYCLOSPORINE } \\
\text { GROUP( } n=16)\end{array}$ & p value ${ }^{*}$ \\
\hline & $\operatorname{MEAN}(95 \%$ C I**) & MEAN $(95 \%$ C I**) & \\
\hline BASLINE & $4.875(4.07-5.67)$ & $4.5(3.88-5.11)$ & $p=0.43$ \\
\hline $2^{\text {ND }}$ WEEKS & $\begin{array}{l}4.18(3.60-4.78) \\
p=0.91\end{array}$ & $\begin{array}{l}4.0(3.56-4.43) \\
p=0.91\end{array}$ & $p=0.59$ \\
\hline $4^{\mathrm{TH}}$ WEEKS & $\begin{array}{l}3.375(2.73-4.01) \\
p=0.134\end{array}$ & $\begin{array}{l}3.06(2.53-3.59) \\
p=0.134\end{array}$ & $p=0.43$ \\
\hline $6^{\mathrm{TH}}$ WEEKS & $\begin{array}{l}2.875(2.40-3.34) \\
p=0.03\end{array}$ & $\begin{array}{l}2.5(1.95-3.05) \\
p=0.03\end{array}$ & $p=0.28$ \\
\hline $8^{\mathrm{TH}}$ WEEKS & $\begin{array}{l}3.25(2.75-3.74) \\
p=0.121\end{array}$ & $\begin{array}{l}3.0(2.3-3.67) \\
p=0.121\end{array}$ & $p=0.53$ \\
\hline
\end{tabular}

TABLE 4; TOTAL OBJECTIVE SIGN SCORE (TOSS) AT DIFFERENT VISITS

* $t$ test for difference of mean ** confidence interval

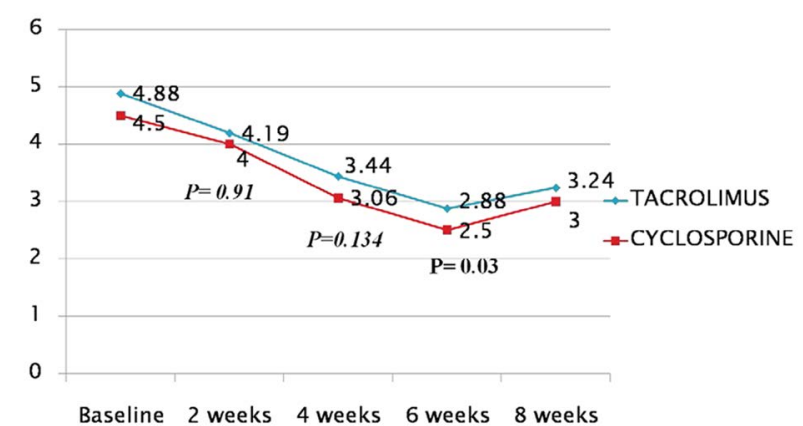

Fig 4. Graphical plot of total objective sign score at different follow up Conjunctival hyperemia was significantly decreased in both the groups at 4th and 6th week. But no significant difference in papillae (size or number) was detected even at 6th week of treatment in either group. At 8th week (after 2 weeks of discontinuing treatment) increase in TSSS and TOSS was observed in both the groups though it was not statistically significant as compared to baseline. (Table 3 and Table 4). No significant side effect, ocular or systemic, were noted in either group except mild stinging in one patient in Group B (Table 5)

\begin{tabular}{|c|c|c|c|c|}
\hline & \multicolumn{2}{|c|}{ Tacrolimus $(n=16)$} & \multicolumn{2}{|c|}{ Cyclosporine $(n=16)$} \\
\hline & Grade & no(\%) & Grade & no( \%) \\
\hline Burning & & 0 & & 0 \\
\hline Stigning & & 0 & 1 & $1(6.25)$ \\
\hline Ocular pain & & 0 & & 0 \\
\hline Periobital rash & & 0 & & 0 \\
\hline Periorbital odema & & 0 & & 0 \\
\hline headache & & 0 & & 0 \\
\hline
\end{tabular}

\section{Table 5 - Adverse effects}

\section{Discussion}

In this study, both topical treatment of $0.03 \%$ FK-506 ophthalmic ointment and 0.05\% cyclosporine eye drops caused significant decrease in TSSS from 4th weeks onwards. A similar prospective, double-masked, randomized comparative study was conducted by Labcharoenwongs et al,2012, in which twenty-four VKC patients received $0.1 \%$ tacrolimus eye ointment twice-daily for 8 weeks, and the other 24 received cyclosporine A 2\% eye drops for the same duration. This study reported that tacrolimus brought about an improvement of the signs and symptoms of VKC similar to that of cyclosporine A. In addition, this study concluded that cyclosporine A treatment was related to a burning sensation and pain on application, compared with a transient burning sensation which was detected in patients with tacrolimus treatment. Objective ocular signs were found to be more improved with tacrolimus treatment, even though this was not statistically significant. Our study didn't show any significant difference between the efficacy of the two drugs. At the same time there was no ocular side effects in either group. More over the beneficial effect of tacrolimus on signs 
especially on papillary size as mentioned in the above study and many other studies as well was not present in our study. This difference can be attributed to the lower concentration of drugs $(0.03 \%)$ as compared to $0.1 \%$ used in most of the other study.

Topical cyclosporine of various concentrations has been investigated for VKC treatment with varying results. In a 2-week, doublemasked, placebo-controlled trial by Pucci et al, 2002 , topical cyclosporine $2 \%$ resulted in an approximately $40 \%$ reduction in subjective and objective scores by the end of the randomization period. Same concentration of cyclosporine eye drop was tried in a large number of children with VKC from Rwanda, Africa by De Smedt et al,2012. In that study, cyclosporine $2 \%$ eye drop was shown to be as effective as topical dexamethasone during the 4-week study period. In a longer open trial by Spadavecchi et al,2006, utilizing a lower concentration of cyclosporine $(1.25 \%$ and $1 \%)$ for 4 months, a higher degree of benefit in subjective and objective was observed. Difference in efficacy of cyclosporine in various publications could be due to difference in methods for cyclosporine preparation and to difference in disease severity. Our study too showed effectiveness of cyclosporine significant enough at 4weeks, probably because of lower concentration of drug used $(0.05 \%)$. At the same time cyclosporine is notorious for stinging sensation but we didn't get such complaints in our study due to lower concentration of drugs used that on the other hand might be responsible for the relapse of symptoms within 2 weeks of stopping treatment. No literature at present, mentions about the course of the disease after stopping treatment with respect to concentration and duration which needs to be further investigated to exactly quantify the duration of treatment for most effective outcome taking care off the side effects of these immune modulators on long term use. The limitations of our study is a small sample size, short course of treatment. Also since 11 out of 46 patients $(23.91 \%)$ were lost to follow up, not much can be commented on the side effects of the drugs with confidence as stinging or other complication with drugs could be a possible cause of poor compliance and dropout from the study.

\section{Conclusion}

Our study suggests that both tacrolimus and cyclosporine have equal potentials to be used as first line drugs in vernal keratoconjunctivitis. Since the effect of drugs is short lasting so the duration of treatment needs to be investigated further with respect to drug concentration to maintain the phase of remission.

\section{References}

Randleman JB, Wolfe JD, Woodward M, Lynn MJ, Cherwek, H, Srivastava SK (2007). The Resident Surgeon Phacoemulsification Learning Curve. Archives of Ophthalmology, 125(9): 1215.

Bielory L (2000). Allergic and immunologic disorder of the eye. Part II: Ocular allergy. J Allergy ClinImmunol;106:1019-32.

Bleik JH, Tabbara KF (1991). Topical cyclosporine in vernal keratoconjunctivitis. Ophthalmology; 98: 1679-84.

Bonini S (2004). Atopic keratoconjunctivitis. Allergy;59:(Suppl. 78):71-3.

Collum MT (1999). Vernal keratoconjunctivitis. Acta OphthalmolScand; 228 (Suppl):14-6.

Cook EB (2004). Tear cytokines in acute and chronic ocular allergic inflammation. Curr Opin Allergy Clin Immunol;4:441-5.

De Smedt S, Nkurikiye J, Fonteyne Y, Tuft S, De Bacquer D, Gilbert C, Kestelyn P (2012).Topical ciclosporin in the treatment of vernal keratoconjunctivitis in Rwanda, Central Africa: a prospective, randomised, 
double-masked, controlled clinical trial. $\mathrm{Br} \mathrm{J}$ Ophthalmol;96:323-8.

Gupta V, Sahu PK(2001). Topical cyclosporin $\mathrm{A}$ in the management of vernal keratoconjunctivitis. Eye;15:39-41.

Labcharoenwongs P,Jirapongsananuruk O, Visitsunthorn N, etal(2012). Adoublemasked comparison of $0.1 \%$ tacrolimus ointment and $2 \%$ cyclosporine eye drops in the treatment of vernal keratoconjunctivitis in children. Asian Pac J Allergy Immunol; 30:177-184.

Leonardi A (2001). Vernal keratoconjunctivitis: pathogenesis and treatment. ProgRetin Eye Res;21:319-39.

NeumannE, GutmannMJ,Blumenkrantz N, Michaelson IC (1959). A review of four hundred cases of vernal keratoconjunctivitis. Am J Ophthalmol;47:166-72.

Pucci N, Novembre E, Cianferoni A, Lombardi E, Bernardini R, Caputo R, et al (2002). Efficacy and safety of cyclosporine eye drops in vernal keratoconjunctivitis. Ann Allergy Asthma Immunol;89:298-303.

Spadavecchia L, Fanelli P, Tesse R, Brunetti L, Cardinale F,Bellizzi M, et al (2006). Efficacy of $1.25 \%$ and $1 \%$ topical cyclosporine in the treatment of severe vernal keratoconjunctivitis in childhood. Pediatrc Allergy Immunol;17:527-32.
Staphl JL, Barney NP (2004). Ocular allergic disease. Curr Opin Allergy ClinImmunol;4:455-9.

Schreiber SL, Crabtree GR (1992). The mechanism of action of cyclosporine A and FK 506. Immunol Today;13:136-42.

Tabbara KF. Ocular complications of vernal keratoconjunctivitis (1999).Can J Ophthalmol;34:88-92.

Vichyanond $\mathrm{P}$, Tantimongkolsuk C, Dumrongkichaiporn P,Jirapongsananuruk O, Visitsunthorn N, Kosrirukvongs P (2004). Vernal kerotoconjunctivitis; result of a novel therapy with $0.1 \%$ topical ophthalmic FK 506 ointment. J Allergy ClinImmunol;113:355-8.

$>$ There is neither any source of support nor any conflict of interest of any kind associated with the same.

> We would like to acknowledge Dr Alok kumar..statistician AIIMS,Patna for his help in statistical analysis. 